\title{
Gender Identification in Language Other than Mother-Tongue: A Case of Non-Thai Listeners Deciphering a Thai Male Speaker's Gender
}

\author{
Savitri Gadavanij \\ Assistant Professor, Graduate School of Language and Communication, \\ National Institute of Development Administration, Bangkok, Thailand \\ savitri@nida.ac.th
}

\begin{abstract}
This paper explores what factors contribute to distinguishing gay sounding and straight man sounding speech; linguistic cognate or social knowledge and whether the gender of listeners also determines ability in identification. To answer these questions, 286 participants were classified by nationality into 3 groups of participants: Thai listeners as a control group, Zhuang, and Other listeners. They were asked to listen to 12 voice stimuli in Thai from straight and gay men and identify the gender of the speakers. The outcome revealed that the accuracy rate in identifying a speaker's gender varied among the 3 groups of listeners with Thai listeners scoring the highest in gender identification, followed by the Others and Zhuang respectively. This indicates that social knowledge gained from one's presence Thailand is more important than linguistic cognate. Gender identification may have been made based on the expectation of the 'typical' social scene such as the high visibility of gay men in Thailand. The results also suggest that gender of the listeners does not have a significant bearing on the ability to differentiate gay and straight male voices.
\end{abstract}

\section{Keywords}

gay sounding speech - gender - Thai 
People's gender identity can be displayed and perceived by visual cues such as how the person is dressed, what hair style he/she has and how he/she behaves. Gender is socially and culturally constructed (Wardhaugh and Fuller 2015, 313). The cue that is taken as an index of gender identity such as masculine or feminine, in one culture may not be considered to be so in another. Linguistic resources may serve as cues that are culturally coded as feminine or masculine or queer. These cues may be negotiated or contested in the performance of gender in discourse (Meyerhoff and Ehrlich 2019, 46o).

Focusing on the LGBT group, there is a popularly held belief that gay men have their own distinct speech style. In Thailand, most Thais believe that they can tell whether a Thai man is straight or gay by listening to his speech. Although in the academia, the trend is moving towards gender fluidity; meaning that people's gender is by no means fixed and that people do not necessarily behave in accordance with their gender, the idea of gender stereotypes is still pervasive among the general public. Being identified as gay does not only label a person by his gender and sexual orientation. It potentially leads to further discrimination based on a set of stereotypical traits associated with a particular gender. Research into sexuality priming or priming gender have proven that the activation of a stereotype potentially leads to subsequent judgements and beliefs (see Hundhammer and Mussweiler 2012, Rudman and Phelan 2010 for examples)

Many studies have yielded findings indicating that a voice cue alone is not enough to tell one's gender identity. However, those studies have been conducted on European languages in the European and North American context, such as the study conducted on English language (Pierrehumbert, Bent, Munson, Bradlow, and Bailey 2004), German (Sulpizio, Fasoli, Maas, Paladino, Vespignani, Eyssel and Bentler 2015), Italian (Sulpizio, Fasoli, Maas, Paladino, Vespignani, Eyssel and Bentler 2015) and Czech (Valentova and Havlicek 2013). It is argued, at least in the case of English language, that one's perceptions of gay sounding voices are language or even dialect specific (Zimman 2013). Speakers of different languages may not be able to distinguish 'gay sounding speech' spoken in languages other than their own.

Based on previous work on Thai perceptions of, and Thai attitudes towards, gay sounding speech (Osatananda and Gadavanij 2019), it was found that $89.11 \%$ of Thai teen listeners can accurately identify straight male speakers while $92.91 \%$ can accurately identify gay speakers by listening to their speech in Thai. By accurate, the study refers to when the listener identifies gender that corresponds with the gender that the speaker says that $\mathrm{s} / \mathrm{he}$ is. The ability to 
identify the gender of a speaker appears to be relatively consistent across the gender groups of listeners. Accuracy in identification also correlates with the level of confidence the listeners have about their answer: not only that Thai listeners are able to identify a speaker's gender, they are also confident about their answer. The findings of the research imply that there are voicing characteristics associated with gay speech in Thai and that these characteristics can be picked up by members of Thai society.

Research into gender identification from speech is also interested in the effect of a listener's gender on the accuracy in gender identification. Linville (1998), for example, speculates that female listeners might be more accurate in identifying the gender of speakers than male listeners are. Osatananda and Gadavanij (2019), however, prove that the listener's gender has no significant effect on the accuracy rate.

This current experimental research, however, explores the issue of language and gender beyond this linguistic community boundary. It investigates the factors determining our judgement of a speaker's gender, illustrating whether people of different linguistic and/or social backgrounds can actually judge a speaker's gender from a speaker's voice. By gay sounding speech, the research does not reject the idea of gender fluidity nor does it adhere to the paradigm of sexual stereotypes. Gay sounding speech is employed as a tool to investigate the social perception generally held that gender stereotype, at least in vocal characteristics, exists. The design of this study stems from work in social cognition proposing that stereotypes are cognitive structures or categories that affect the encoding and processing of information (Hamilton and Trolier 1986; von Hippel, Sekaquaptewa, and Vargas 1995). The structures direct the attention to some stimuli, in our case it was gendered vocal cues, and away from others that influence categorization of information (Fiske and Taylor 1991; Oliver 1994). Research on speech and perception of gender proposed two types of relationship: one was the idea that the sex of talkers was perceived to be in a dichotomous relationship (male and female) and another was that sex and voice were perceived gradiently (a spectrum of prototypical male to prototypical female) (Strand 1999, 89).

Moreover, this research aims to further investigate what constitutes a listener's perception of 'gendered vocal cues'. It asks if such perception is language specific? Can the ability to distinguish a straight man and a gay man from speech be maintained in a cross-lingual context? And what factors contribute to the recognition of such voicing characteristics as index of gay? This study tests 2 factors, namely, linguistic cognate and the social background. The current study selects 2 groups of listeners based on their native language: Zhuang which belongs to the Tai language family and Others (mostly European 
languages). Zhuang speakers represent the subject with linguistic cognate but lack the social background of Thailand and Others speakers traveling in Thailand represent the subject with an awareness of gay men in Thai society but who lack a common linguistic background. The study sheds light on the performance of gayness in speech as well as contribute more insight into the nature and system of language in cross-lingual interaction.

\section{2}

\section{Hypotheses}

1. Accuracy rate in gender identification differs significantly among the 3 groups of listeners with different backgrounds: Thai, Zhuang and Others. Thai listeners would be the most accurate group, followed by Zhuang and Others respectively.

2. The speakers of Zhuang will be able to identify the gender of Thai speakers more accurately than speakers of other languages. Based on Zimman (2013) the perception of gay sounding speech is language or dialect specific, Zhuang listeners whose native language is akin to Thai should be able to decode the gendered speech more accurately than Others.

3. In line with Osatananda and Gadavanij (2019), it is argued that the gender of the listeners has no bearing on the accuracy of gender identification.

\section{Literature Review}

The work takes the philosophical stance of social constructionism. The method of analysis is designed on the basis of Practice theory's assumption that social identity is constituted through social action (Eckert and McConnell-Ginet 1992).

Eckert and McConnell-Ginet's (1992) notion of performativity and Butler's (1990) idea of gender as performative. People do not express their preexisting gender. Instead, it is argued that gender identity exists in the speaker's expression (Meyerhof and Ehrlich 2019, 460). People 'do gender' in interaction.

Earlier studies were conducted based on the hypothesis that differences in speech production among speakers of different genders are part of the difference in language register that is used in the attempt to identify one's sexual orientation. Studies done by linguists involved a comparison of speech between groups of male and female speakers. The aim was to develop some understanding of the forms that constitute femininity and masculinity in speech (Lakoff 1975; Coates 1986), recognition of differences in speech style 
(Maltz and Borker 1982) and the social meaning of such styles and forms (McConnell-Ginet 1983; Henton 1989). These studies emphasized rigid demarcation between genders and investigated only a similarity-difference axis. With the same empirical method and acoustic measurement, there are also studies that account for intragroup diversity. Instead of classifying language as belonging to male or female speakers, Terango (1966) investigates speech in terms of its masculine-effeminate style. The continuum between the two styles gives rise notion of diversity in performance even among same sex speakers. Features that contribute to masculine and feminine style are the median fundamental frequency, average rate of pitch change during inflections and the mode of average fundamental frequency (for more information, see Terango 1966).

With increasing interest in queer studies over the past couple of decades, the number of studies on speech of LG BTQ has risen. In previous studies such as Pierrehumbert et al. (2004) and Munson et al. (2006), it was hypothesized that the differences in speech style of gay and lesbian (GLB) and heterosexual people did not come from anatomical differences but they were a learned way of speaking and register that indicated sexual orientation. The argument resonates with Butler's proposition that gender identity, in this case queer identity, is performed and emerged in interaction.

Findings of previous studies on male speech have proved that there are discernible differences between straight men's and gay men's speech. They argued that gay men would produce certain voice cues that are different from the normative masculine voice. Avery and Liss (1994) found that gay and lesbian and heterosexual speakers differ in sentence- level pitch variation and in the frequency of the fricative /s/; GLB displays greater variation and higher center frequencies of the fricatives $/ \mathrm{s} /$ than heterosexual speakers do.

In the analysis of heterosexual men's and gay men's speech, Linville (1998) confirmed Avery and Liss (1994)'s finding that the speech production of the 2 groups varied, indicating that there was a difference in the duration and spectrum of /s/ (Linville 1998 cited in Pierrehumbert et al. 2004, 1905). Pierrehumbert et al., (2004) studied the influence of sexual orientation on vowel production and found that gay men produced a more expanded vowel space than heterosexual men.

Munson et al., (2006)'s studies on gay speech alluded to the different acoustic properties of /ae/ and /E/ produced by gay men and heterosexual men, as well as the difference in the spectral displays of /s/ produced by the two groups. Specifically, they reported that the Fivalue in /ae/ and /E/ produced by gay men was higher than the one produced by heterosexual men and that the spectrum of /s/ produced by the two groups displayed different shapes. 
Despite a large number of production-based studies on language and gender, the first study that took into account the perception of the listeners was Moonwomon-Baird's research on intragender group (Moonwomon-Baird 1985). The study investigated the voicing characteristics of lesbians. Her findings connected socially expected gender stereotypes and phonological realization, arguing that heterosexual women were more likely to conform to gender-based stereotypes than their lesbian counterparts. The same was also expected in the case of heterosexual men compared to their gay counterparts.

Gaudio (1994)'s study on gay speech is a classic study that investigated acoustic features as well as listeners' perception in parallel. The findings of the acoustic analysis in relation to listeners' perception confirmed that, of the previous research, overall pitch range and pitch variability were not determining factors of gay sounding speech. Yet listeners were quite consistent in judging what speech sounded gay and they were largely accurate in identifying the speaker's sexual orientation from their speech.

Ron Smyth and Henry Rogers have published key studies on gay sounding speech using a sociophonetic approach to gender. Their works, Smyth and Rogers (2002) and Rogers and Smyth (2003), investigated the correlation between phonetic characteristics and gender in North American English. The experiment revealed that pitch (fundamental frequency, Fo) and formant frequencies were not cues for speaker's sexual orientation (Rogers and Smyth 2003,1856 ). Though there seems to be a complexity in how those features work together and to what extent each factor contributes to the gender rating on the part of the listeners, one thing clearly presented in Rogers and Smyth (2003) is that people hold a belief in stereotypical traits associated with gay men's voices. A gay voice is believed to be higher and have more exaggerated intonation than straight men's (Rogers and Smyth 2003, 1857).

A study on gay sounding speech that has objectives and scope related to this current research is the one conducted by Linville (1998). In her paper, she explored the differences in speech patterns to see how these related to the perceived and actual sexual orientation of the speakers. It was reported that the listeners could correctly identify the gender of the speaker $79.6 \%$ of the time. This confirms Gaudio (1994)'s finding that a speaker's gender is discernible from speech characteristics. The findings also suggested bias towards identifying speakers as straight. Linville also questioned whether the gender of listeners who were all female may contribute to the high accuracy rate. She also speculated that male listeners might not be able to identify gender as accurately as female ones.

Calahaly's work responds to the call of Linville. In her MA thesis, Calahaly asked 8 o subjects to identify the gender of 40 speakers of voice samples who 
were classified as gay/ lesbian, straight men and straight women (Calahaly 200o). The experiment also classified the listeners into the same 4 gender groups. It was found that listeners could correctly identify the gender of speakers at $70.7 \%$ accuracy. Gay and lesbian subjects were more accurate in identifying the sexual orientation of female speakers. This study suggests that the gender of the listener plays a part in gender identification.

The current studies focus on the perception of the listeners, exploring the factors that contribute to the listener's perception and accuracy in gender identification in cross-lingual interaction. Based on the previous research (Osatananda and Gadavanij 2019), I postulate that members of the same gender identity group may not and cannot engage in linguistic interaction in an exactly similar manner. They only display features sufficiently similar to be classified as coming from the same group and different enough to be distinctive from other groups. Though there may be diversity in the voice of in-group members, I hypothesize that there are enough similarities that contribute to authenticate perceptible gay sounding speech. Therefore, instead of trying to establish an acoustic pattern of gay speech using a computer-assisted voice analysis program, attention is directed to listener perception. It is argued that people's perception can indicate whether the voice sounds distinctively gay or not.

Since this study aims to investigate an audience of varying background's interpretation of voicing characteristics, in the experiment, the subjects only listen to the audio recording of the speech. All other visual cues are eliminated. This research singled out voicing characteristics as one of the micro units that can be considered in the linguistic resource that indexes gender identity (Bucholtz and Hall 2005).

\section{Methodology}

\subsection{Speakers}

The project started by recruiting male volunteers from 2 universities in Bangkok to participate in the experiment. First, they had to come from Bangkok and speak standard Thai. This criterion was implemented to avoid dialect interference in the voice sample. Second, they had to be willing to reveal their gender identity. 12 speakers were recruited to participate in this experiment. They were asked to check the box for their corresponding gender: gay or straight. 6 self-identified as gay and 6 self-identified as straight men. All of them were aged between 18 to 22 years old and were studying for their Bachelor degrees. 


\subsection{Speaker's Task}

Each subject was asked to read a 410-word news article about a car accident that killed a famous teenage DJ. After the reading, the subjects were asked to re-narrate this news in their own words to an imaginary friend of the same gender as if he were engaging in a casual conversation. With the context given, the re-narration of familiar news to a friend of the same gender generated a casual conversation style. Only the 30 -second recording in the middle of the talk was collected as it was considered to be the most natural segment of speech. The 12 voice stimuli were coded as GM for gay man and SM for straight man. Each stimulus had a number assigned, making it SM1-6 and GM 1-6.

\subsection{Listeners}

286 listeners were recruited to participate in this research. They were classified into 3 groups by their native language: Thai $(34.96 \%)$, Others $(34.27 \%)$ and Zhuang $(30.77 \%)$ listeners.

The classification of the participants was part of the design to test the primary variables, namely, linguistic background and sociocultural knowledge about Thailand. 100 Thai participants were the control group, having both the linguistic background and social/cultural knowledge. 98 Others participants were tourists who were staying in Thailand for less than a month, with the majority of them spending 1-3 weeks. None had taken any Thai language course. For the group comprising people with varying native language except Thai or any of the Tai language family. Except for a few Korean speakers, participants in this group all speak Western languages such as Spanish, English, French, German, Polish, and Dutch.

According to UN Resident Coordinator and UNDP Resident Representative for Thailand, Luc Stevens, "Thailand is one of the few countries in the AsiaPacific region where the LGBT community has high visibility" (Thailand's LGBT Communities Continue to Face Social Stigma Despite Visibility: Comprehensive UN-US Country Report).

Given their presence in Thailand, the Others group represents listeners who have exposure to the Thai gay population, thus having sociocultural knowledge and awareness about the prevalence of gays in Thailand but who lack the linguistic background.

On the other hand, the 88 Zhuang participants, all of whom had Zhuang as their native language, were recruited using snowball sampling. They participated in the experiment in Yunnan province, China. Most of them had never been to Thailand (90.91\%). This group represents participants with linguistic 
cognate but lacking in sociocultural knowledge and awareness of the prevalence of Thai gay.

The gender distribution of all the listeners was also tested to see if it determined one's ability for gender identification. The participants were asked to tick the box of their corresponding gender from 5 available boxes: straight man, gay man, straight woman, lesbian and not specified. The distribution of listener's gender among Thais which were the control group and the non-Thais which were the target group is presented in the Table 1.

TABLE 1 Gender of Listeners

\begin{tabular}{lcccccc}
\hline Gender (listeners) & \multicolumn{2}{c}{ Thai } & \multicolumn{2}{c}{ Non-Thai } & \multicolumn{2}{c}{ Total } \\
& $\begin{array}{l}\text { Number } \\
\text { (persons) }\end{array}$ & $\%$ & $\begin{array}{c}\text { Number } \\
\text { (persons) }\end{array}$ & $\%$ & $\begin{array}{c}\text { Number } \\
\text { (persons) }\end{array}$ & $\%$ \\
& 16 & 16.00 & 85 & 45.21 & 101 & 35.07 \\
Straight man & 17 & 17.00 & 8 & 4.26 & 25 & 8.68 \\
Gay man & 56 & 56.00 & 90 & 47.87 & 146 & 50.69 \\
Straight woman & 11 & 11.00 & 4 & 2.13 & 15 & 5.21 \\
Lesbian & 0 & 0.00 & 1 & 0.53 & 1 & 0.35 \\
Not specified & 100 & 100.00 & 188 & 100.00 & 288 & 100 \\
Total & & & & & &
\end{tabular}

\subsection{Listener's Task}

Listeners were given a form to fill in their personal information about their gender, age and whether/ how long s/he had been in Thailand. The forms were compiled in 3 languages: a Thai form for Thai listeners, a Mandarin Chinese form for Zhuang listeners who, despite their Zhuang mother-tongue, use Mandarin Chinese as their official language and English for Others.

The 12 thirty-second voice stimuli were played in random order to listeners who were asked to identify the speaker who was gay or straight by ticking the appropriate box provided on the form within a 5 -second interval between stimuli. The average rates of accuracy are given in Table 2.

\section{5}

\section{Analysis and Findings}

A one-way analysis of variance (ANOVA) reveals that Thai listeners were the most accurate. In terms of the ability to identify gender identity, the Thai listeners showed the best performance, followed by Others and Zhuang listeners respectively. Thai listeners could accurately identify an average of 5.73 out of the 6 gay voice stimuli samples, and 4.58 out of the 6 straight man voice stimuli 
TABLE 2 Average rates of accuracy in gender identification by the 3 groups of listeners

\begin{tabular}{llrrr}
\hline Voice stimuli & Listeners & Number (person) & Score average & S.D \\
\hline \multirow{2}{*}{ Total: 6 GM s } & Thai & 100 & 5.73 & 0.62 \\
& Others & 98 & 4.38 & 1.16 \\
& Zhuang & 88 & 2.55 & 1.57 \\
& Total & 286 & 4.29 & 1.74 \\
Total 6 s M s & Thai & 100 & 4.58 & 1.16 \\
& Others & 98 & 4.09 & 1.27 \\
& Zhuang & 88 & 3.06 & 1.49 \\
& Total & 286 & 3.94 & 1.44 \\
Total (12 voices) & Thai & 100 & 10.31 & 1.38 \\
& Others & 98 & 8.47 & 1.82 \\
& Zhuang & 88 & 5.60 & 3.29 \\
& Total & 286 & 8.23 & 2.66 \\
& & & & \\
\hline
\end{tabular}

samples. Of all the 12 stimuli, Thai listeners were able to identify an average of 10.31 cases. Others listeners were able to accurately identify an average of 4.38 out of 6 gay voices, 4.09 out of 6 straight man voices and 8.47 out of the entire 12 voice stimuli. Zhuang participants could accurately identify an average of 2.55 out of the 6 gay voices, 3.06 out of the 6 straight man voices and 5.6o out of the entire 12 voice stimuli.

Thai listeners' accuracy peaked in the case of gay voices. This result can be interpreted in 2 ways. One is that Thai listeners are more acute in detecting gay voice production. Another is that Thais are inclined to identify male voices as those of gay people. Since there are only 2 possible answers: gay or straight, opting for gay most of the time can result in a higher accuracy rate when they identify gay speakers. This is supported by an observation which found that the Thai accuracy rate drops with the identification of straight male voices.

The voice samples that posed a problem of gender identification for Thai listeners were those of straight men, particularly in samples $\mathrm{SM}_{1}, \mathrm{SM}_{4}$ and $\mathrm{SM}_{5}$. In identification of these 3 voice stimuli, the group of Others listeners performed better compared to Thai listeners with an accuracy rate of gender identification at 87:76, 87:81 and 6o:57 respectively. There may have been certain voice qualities seen as an indicator of gayness to Thai listeners in these 3 voices. However, this quality was not interpreted as such by the 2 non-Thai listener groups. This point requires further investigation.

Zhuang listeners, however, consistently scored the lowest in identification. Comparing accuracy rate among the 3 groups of listeners, it is clear that the accuracy rate of Thai listeners surpassed that of the other groups of listeners 
in all the voice stimuli, except for voices $\mathrm{SM}_{1}, \mathrm{SM}_{4}$ and $\mathrm{SM}_{5}$. These 3 stimuli were the voices of straight males, softly spoken. In these cases, the accuracy rate of Thai listeners decreased and was surpassed by the accuracy rate of Others listeners who scored relatively equally in all voice stimuli. The problem of identification of straight male voices by Thai listeners has been reported in Osatananda and Gadavanij (2019). Apart from the cases of the 3 voice stimuli mentioned, the ranking is consistent with Thai, Others and Zhuang both in the identification of gay and straight male voices.

Comparing the accuracy rates in identifying gay and straight male voices, both Thai and Others listeners scored less in the identification of straight male voices. To put it plainly, Thai and Others listeners were more likely to confuse straight male voice with gay's than vice-versa. Their awareness of the prevalence of gays in Thailand might have influenced their decision in this case.

The opposite, however, is true in the case of Zhuang listeners, who identified gay voices as those of straight men. This observation is supported by the group average score of 2.55 out of 6 in gay voice identification.

When comparing the results of gender identification of 12 voices of Thai listeners classified by their gender, it was found that Thai female listeners received the highest score in the overall gender identification of 12 voices (10.54/12) and the identification of straight male voices (4.80/6). This confirms Linville's speculation that male listeners may not identify gender as accurately as female ones (Linville 1998). However, when it comes to identifying gay voices, Thai gay men performed the best among all the 4 groups, scoring an average of $5 \cdot 76 / 6$.

Comparing accuracy rates across the 3 groups using Pearson Chi-Square, it is found that Thai accuracy rate was significantly higher than other groups. This observation derives from statistical differences in the rate of accuracy in gender identification among the 3 groups of listeners with $\mathrm{P}=0.00$ in almost every voice stimulus except $\mathrm{SM}_{5}$, in which case Thai listeners's accuracy dropped, rendering accuracy comparable to that of listeners in other groups $(\mathrm{P}=0.655)$.

\section{Discussion}

To prove our first hypothesis, that the 3 groups of listeners would display different accuracy rates in gender identification, ANOVA was used to compare the significance of the mean scores of all groups. The analysis points to a statistically significant difference $(P=0.000)$ as shown in Table 3 .

On closer examination, multiple comparison was used to see the correlations in rating among the 3 groups. The results are shown in Table 4. 
TABLE 3 Comparison of accuracy in gender identification among 3 groups of listeners

\begin{tabular}{lrrrrr}
\hline \multicolumn{5}{c}{ ANOVA } \\
& Sum of Squares & Df & Mean Square & F & Sig. \\
\hline Between Groups & 1045.892 & 2 & 522.946 & 153.381 & .000 \\
Within Groups & 964.878 & 283 & 3.409 & & \\
Total & 2010.769 & 285 & & & \\
\hline
\end{tabular}

Table 4 shows that the rate of accuracy is significantly different in every pattern of pair comparison among the 3 groups $(\mathrm{P}=0.00)$. This leads us to prove the 1st hypothesis valid. Thai listeners, non- Chinese listeners and Chinese listeners display varying degrees of accuracy. The difference is statistically significant.

TABLE 4 Multiple comparison of accuracy in gender identification among the 3 groups of listeners, grouped by their linguistic background

\begin{tabular}{|c|c|c|c|c|c|c|}
\hline \multicolumn{7}{|c|}{ Post Hoc Tests Multiple Comparisons } \\
\hline \multirow[t]{2}{*}{ (I) type } & \multirow[t]{2}{*}{ (J) type } & \multirow[t]{2}{*}{$\begin{array}{c}\text { Mean } \\
\text { Difference }(\mathrm{I}-\mathrm{J})\end{array}$} & \multirow[t]{2}{*}{$\begin{array}{l}\text { Std. } \\
\text { Error }\end{array}$} & \multirow[t]{2}{*}{ Sig. } & \multicolumn{2}{|c|}{$\begin{array}{c}\text { 95\% Confi- } \\
\text { dence Interval }\end{array}$} \\
\hline & & & & & $\begin{array}{l}\text { Lower } \\
\text { Bound }\end{array}$ & $\begin{array}{l}\text { Upper } \\
\text { Bound }\end{array}$ \\
\hline \multirow[t]{2}{*}{ Thai } & Others & $1.841^{*}$ & .262 & .000 & 1.19 & 2.49 \\
\hline & Zhuang & $4.708^{*}$ & .270 & .000 & 4.04 & $5 \cdot 37$ \\
\hline \multirow[t]{4}{*}{ Others } & Thai & $-1.841^{*}$ & .262 & .000 & -2.49 & -1.19 \\
\hline & Zhuang & $2.867^{*}$ & .271 & .000 & 2.20 & $3 \cdot 53$ \\
\hline & Thai & $-4.708^{*}$ & .270 & .000 & $-5 \cdot 37$ & -4.04 \\
\hline & Others & $-2.867^{*}$ & .271 & .000 & -3.53 & -2.20 \\
\hline
\end{tabular}

*The mean difference is significant at the 0.05 level.

We then moved on to prove our and hypothesis, that the listener's linguistic background plays a primary role in determining accuracy in gender identification. To test this hypothesis, the performance of 2 groups of the participant listeners was focused upon: Others, who represent listeners with social knowledge but lack linguistic knowledge, and the Zhuang, who represent people with a linguistic background akin to Thai. 
TABLE 5 Comparison of accuracy in gender identification between groups of Others listeners (with social knowledge) and Zhuang listeners (with linguistic knowledge)

\section{Correlation}

\begin{tabular}{llccc}
\hline & & & \\
& & & \\
& & & \\
Sationality & Language & Sum total \\
\hline \multirow{5}{*}{ Linguistic knowledge } & Pearson Correlation & 1 & $.971^{* *}$ & $-.682^{* *}$ \\
& Sig. (2-tailed) & & .000 & .000 \\
& N & 286 & 286 & 286 \\
Sum total & Pearson Correlation & $.971^{* *}$ & 1 & $-.680^{* *}$ \\
& Sig. (2-tailed) & .000 & & .00 \\
& N & 286 & 286 & 286 \\
& Pearson Correlation & $-.682^{* *}$ & $-.680^{* *}$ & 1 \\
& Sig. (2-tailed) & .000 & .000 & \\
& N & 286 & 286 & 286
\end{tabular}

** Correlation is significant at the o.o1 level (2-tailed).

Table 5 above shows that both sets of background knowledge, linguistic and social, significantly contribute to the listener's ability to tell speakers' genders. $(\mathrm{P}=0.000)$. In order to prove the 2 nd hypothesis, we compared the performance of the 2 groups: Others and Zhuang listeners. Each was representative of listeners with social knowledge and linguistic knowledge respectively. It is argued that the rate of accuracy of each group can indicate which set of knowledge plays the more significant role.

According to Table 6 and 7 , in identifying gay speakers, most Others listeners could correctly identify 4-5 out of 6 voices. On the other hand, most Zhuang listeners could correctly identify only 1-2 out of 6 gay voices. This indicates that most Zhuang mistook the voices of gays as those of straight men. It confirms that Zhuang had a bias towards identifying voices as those of heterosexual men. The difference in accuracy between the two groups of listeners is significant as shown in the statistic record $(\mathrm{P}=0.000)$.

TABLE 6 Summary of correct response for gay voice classified by group

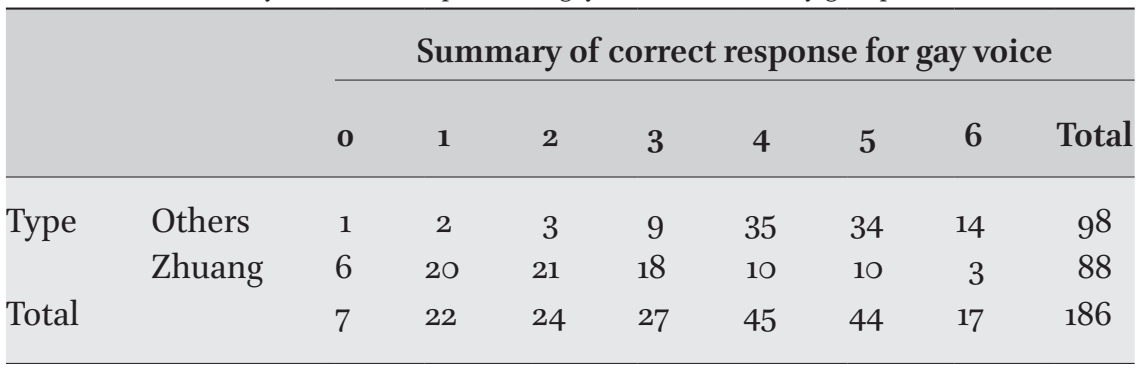


TABLE 7 Comparison of response classified by group

\begin{tabular}{lllc}
\hline & Value & Df & Asymp. Sig. (2-sided) \\
\hline Pearson Chi-Square & $68.557^{*}$ & 6 & .000 \\
Likelihood Ratio & 75.029 & 6 & .000 \\
Linear-by-Linear Association & 57.528 & 1 & .000 \\
N of Valid Cases & 186 & & \\
\hline
\end{tabular}

In identifying straight male speakers, most of the Others listeners could correctly identify 4 out of 6 voices while most of the Zhuang listeners correctly identified 3 out of 6 voices. It can be seen that the difference in accuracy rates of the two groups does not differ as much as in the case of gay voices. Yet, Table 9 shows the difference is still statistically significant $(\mathrm{P}=0.000)$.

The fact that Zhuang participants- scored significantly lower than Others listeners for the voices of both genders indicating that the social background that the Others listeners had plays a more important role in determining the

TABLE 8 Summary of correct responses for straight male voice classified by group

\begin{tabular}{|c|c|c|c|c|c|c|c|c|c|}
\hline \multicolumn{10}{|c|}{ Crosstab } \\
\hline & & \multicolumn{8}{|c|}{ Summary of correct response for straight male voice } \\
\hline & & $\mathbf{0}$ & 1 & 2 & 3 & 4 & 5 & 6 & Total \\
\hline \multirow[t]{2}{*}{ Type } & Others & 1 & o & 11 & 17 & 31 & 24 & 14 & 98 \\
\hline & Zhuang & 2 & 13 & 18 & 21 & 17 & 13 & 4 & 88 \\
\hline Total & & 3 & 13 & 29 & 38 & 48 & 37 & 18 & 186 \\
\hline
\end{tabular}

TABLE 9 Comparison of response classified by group

\begin{tabular}{llll}
\hline & Value & Df & Asymp. Sig. (2-sided) \\
\hline Pearson Chi-Square & $27.896 \mathrm{a}$ & 6 & .000 \\
Likelihood Ratio & 33.299 & 6 & .000 \\
Linear-by-Linear Association & 23.055 & 1 & .000 \\
N of Valid Cases & 186 & & \\
\hline
\end{tabular}

a. 2 cells $(14.3 \%)$ have expected a count of less than 5 . The minimum expected count is 1.42 
accuracy in gender identification than the linguistic background that the Zhuang listeners had. Hence this finding proves that our and hypothesis is valid. It is argued that gender has a social meaning which the listeners have to rely on to make the indexical connection between meaning making resources audible in the interaction and the social meaning, in this case gender. Such connection can only be acquired when listeners are immersed in, or significantly exposed to, the discursive community in which the interaction takes place.

Tables 10 and 11 show the results related to our 3 rd hypothesis: gender of listeners will not affect accuracy in gender identification. The first table shows the ANOVA result comparing the accuracy rate of listeners grouped by their gender. The difference is not significant among groups $(\mathrm{P}>0.05)$.

To investigate the rating of each group of listeners in more detail, multiple comparison was used to see if there was any significant difference between various patterns of pair comparison. The result shows no significant difference $(\mathrm{P}>0.05)$. This means that gender is not a determining variable in gender identification. Thus, it proves our 3 rd hypothesis valid.

The findings of this research outlined the proposition that identity is discursively constructed in a communicative context. Gender identity can be expressed by certain vocal characteristics and it will succeed in communicating gender only when the listeners interpret them as such. Since the connection is not straight forward, people with varying backgrounds may interpret the same voicing characteristics differently depending on the norm of male speech that they hold. Understanding of the language and its standard pronunciation may contribute to such a norm. The finding confirms Osatananda and Gadavanij (2019) in that though straight man and gay man speech bears certain discernible features associated with such gender, there are variations within each speech style. While gay sounding speech is understood to diverge from the norm of masculinity, some gay men may sound more effeminate than others. With such variations, no clear demarcation between gay and straight man sounding speech can be found. People, then, rely on social knowledge

TABLE 10 Comparison of accuracy rate in gender identification of listeners grouped by gender

\begin{tabular}{lccccr}
\hline & Sum of Squares & Df & Mean Square & F & Sig. \\
\hline Between Groups & 37.768 & 3 & 12.589 & 1.794 & .148 \\
Within Groups & 1971.481 & 281 & 7.016 & & \\
Total & 2009.249 & 284 & & & \\
\hline
\end{tabular}


TABLE 11 Multiple comparison of accuracy in gender identification among the 3 groups of listeners grouped by their gender

\begin{tabular}{|c|c|c|c|c|c|c|}
\hline \multicolumn{7}{|c|}{ Post Hoc Tests Multiple Comparisons } \\
\hline \multirow[t]{2}{*}{ (S) gender } & \multirow[t]{2}{*}{ (L) gender } & \multirow[t]{2}{*}{$\begin{array}{c}\text { Mean } \\
\text { Difference (I-J) }\end{array}$} & \multirow[t]{2}{*}{$\begin{array}{l}\text { Std. } \\
\text { Error }\end{array}$} & \multirow[t]{2}{*}{ Sig. } & \multicolumn{2}{|c|}{$\begin{array}{c}\text { 95\% Confi- } \\
\text { dence Interval }\end{array}$} \\
\hline & & & & & $\begin{array}{l}\text { Lower } \\
\text { Bound }\end{array}$ & $\begin{array}{l}\text { Upper } \\
\text { Bound }\end{array}$ \\
\hline \multirow[t]{3}{*}{ Straight male } & Gay & -1.132 & .593 & .305 & -2.80 & .54 \\
\hline & $\begin{array}{l}\text { Straight } \\
\text { female }\end{array}$ & -.487 & $\cdot 345$ & .575 & -1.46 & .48 \\
\hline & Lesbian & -1.105 & .734 & $\cdot 520$ & -3.17 & .96 \\
\hline \multirow[t]{3}{*}{ Gay } & Straight male & 1.132 & .593 & .305 & -.54 & 2.80 \\
\hline & $\begin{array}{l}\text { Straight } \\
\text { female }\end{array}$ & .645 & .573 & $\cdot 738$ & -.97 & 2.26 \\
\hline & Lesbian & .027 & .865 & 1.00 & -2.41 & 2.46 \\
\hline \multirow{3}{*}{$\begin{array}{l}\text { Straight } \\
\text { female }\end{array}$} & Straight male & .487 & $\cdot 345$ & .575 & -.48 & 1.46 \\
\hline & Gay & -.645 & .573 & .738 & -2.26 & .97 \\
\hline & Lesbian & -.618 & .718 & .863 & -2.64 & 1.40 \\
\hline \multirow[t]{3}{*}{ Lesbian } & Straight male & 1.105 & .734 & .520 & -.96 & 3.17 \\
\hline & Gay & -.027 & .865 & 1.000 & -2.46 & 2.41 \\
\hline & $\begin{array}{l}\text { Straight } \\
\text { female }\end{array}$ & .618 & .718 & .863 & -1.40 & 2.64 \\
\hline
\end{tabular}

about 'what can be expected' in that context in establishing the link between the voice stimuli and the interpretation (Osatananda and Gadavanij 2019, 46-47). Listeners who have less awareness of the gay population would not identify the voice as that of gay even when it sounds feminine. The effeminate voice cue will be deemed as an individual characteristic, a variation within the spectrum of male speech, as found in the case of Zhuang listeners. According to the findings, linguistic cognate and gender of the listeners have little influence on the interpretation.

\section{$9 \quad$ Conclusion}

This article discussed the discursive construction of gay gender identity focusing on the listener's perception of such identity. Taking a social constructivist 
viewpoint about identity, the research looked at the construction of identity in interactions with specific interest paid to voice cues. 3 groups of people, with a total of 298 listeners, were asked to listen and identify the gender of the speakers of 12 voice samples. A Thai listeners group represented the standard to test the validity of voice cues while 2 groups of participants, Others foreigners and Zhuang groups, represented listeners with the linguistic background and with social background respectively. Within each group, listeners were classified into 5 gender groups. The results reveal that Thai listeners display the highest level of accuracy. This may be the result of both the linguistic knowledge and social knowledge that they possess. When compared to the performance between the other 2 groups, it is clear that Others can do better than Zhuang listeners. This means that the familiarity with certain language features, in this case, the tonal system, of Zhuang does not contribute to the interpretation of social meaning associated with certain characteristics of linguistic interaction. In the case of gender identity indexed by voice cues, social background, social experience in the communicative context and some exposure with the community as in the case of Others listeners appear to be more influential. However, it would be interesting to investigate in further research, which cues listeners use as an indicator of gayness and how the correlation between the cue and gender is established in interaction.

\section{Disclosure statement}

This research has no potential conflict of interest.

\section{Acknowledgments}

This research is funded by the Graduate School of Language and Communication, National Institute of Development Administration. I also would like to thank Associate Professor Dr Varisa Osatananda for her support and suggestions on an earlier draft of this paper.

\section{References}

Avery, Jack D., and Julie M. Liss. 1994. "Acoustic Characteristics of Less-MasculineSounding Male Speech." Journal of the Acoustical Society of America 99 (6): 3738-3748. 
Bucholtz, Mary, and Kira Hall. 2005. "Identity and Interaction: A Sociocultural Linguistic Approach." Discourse Studies 7 (4-5):585-614.

Butler, Judith. 199o. Gender Troubles: Feminism and the Subversion of Identity. London: Routledge.

Calahaly, Lynn N. 200o. "Listener Accuracy in Identifying the Sexual Orientation of Male and Female Speakers." MA thesis. Ohio State University.

Coates, Jennifer. 1986. Women, Men and Language: A Sociolinguistic Account of Sex Differences in Language. London: Longman.

Diller, Anthony V.N., Jerold A. Edmondson, and Yongxian Luo. 2008. The Tai-Kadai Languages. London: Routledge.

Eckert, Penelope, and Sally McConnell-Ginet. 1992. "Think Practically and Look Locally: Language and Gender as Community-Based Practice." Annual Review of Anthropology 1992 (21): 461-9o.

Fiske, Susan T., and Shelly E. Taylor. 1991. Social Cognition (2nd ed). New York: McGraw-Hill.

Gaudio, Rudolf P. 1994. "Sounding Gay: Pitch Properties in the Speech of Gay and Straight Men." American Speech 69 (1): 30-57.

Hamilton, David L., and Tina K. Trolier. 1986. "Stereotypes and Stereotyping: An Overview of the Cognitive Approach." In Prejudice, Discrimination and Racism, edited by John F. Dovidio and Samuel L. Gaertner, 127-63. Orlando: Academic Press.

Henton, Caroline G. 1989. "Fact and Fiction in the Description of Female and Male Pitch." Language and Communication 9 (4): 299-311.

Hundhammer, Tanja, and Thomas Mussweiler. 2012. "How Sex Puts You in Gendered Shoes: Sexuality-Priming Leads to Gender-Based Self-Perception and Behaviour." Journal of Personality and Social Psychology 103 (1): 176-193.

Lakoff, Robin. 1975. "Linguistic Theory and the Real World." Language Learning: A Journal of Research in Language Studies 25 (2): 309-338.

Linville, Sue Ellen. 1998. "Acoustic Correlates of Perceived versus Actual Sexual Orientation in Men's Speech." Folia Phoniatrica et Logopaedica 50 (1): 35-48.

Maltz, Daniel, and Ruth Borker. 1982. "A Cultural Approach to Male-Female Miscommunication." In Language and Social Identity, edited by John J. Gumperz, 196-215. New York: Cambridge University Press.

McConnell-Ginet, Sally. 1983. "Review Article". Review of "Language, Sex and Gender: Does 'La Difference' Make Difference?” By Judith Orasanu, Mariam K. Siaster, Leonore Loeb Adler and "Sexist Language: A Modern Philosophical Analysis." by Mary Vettering-Braggin. Language 59 (2): 373-391.

Meyerhoff, Miriam, and Susan Ehrlich. 2019. "Language, Gender and Sexuality." Annual Review of Linguistics 2019 (5): 455-475.

Moonwomon-Baird, Birch. 1985. "Towards a Study of Lesbian Language." In Proceedings of the First Berkeley Women and Language Conference, edited by Sue Bremner, 
Noelle Caskey, and Birch Moonwomon-Baird, 96-107. Berkeley: Berkeley Women and Language Group.

Munson, Benjamin, Elizabeth C. McDonald, Nancy L. DeBoe, and Aubrey R. White. 20o6. "The Acoustic and Perceptual Bases of Judgements of Women and Men's Sexual Orientation from Read Speech." Journal of Phonetics 34: 202-240.

Oliver, Mary Beth. 1994. "Portrayals of Crime, Race and Aggression in "Reality-Based" Police Shows: A Content Analysis." Journal of Broadcasting and Electronic Media 38 (2): 179-92.

Osatananda, Varisa, and Savitri Gadavanij. 2019. "Materializing Gay Identity: A Critical Analysis of Gay Sounding Speech in Thai." Journal of Language and Sexuality 8 (1): $3^{0}-5^{2}$.

Pierrehumbert, Janet B., Tessa Bent, Benjamin Munson, Ann R. Bradlow, and Michael J. Bailey. 2004. "The Influence of Sexual Orientation on Vowel Production." Journal of Acoustic America 116: 1905-8.

Rogers, Henry, and Ron Smyth. 2003. "Phonetics Differences between Gay-and Straight-Sounding Male Speakers of North American English." Proceedings of the 15th International Congress of Phonetics Sciences, Barcelona, 3-9 August 2003: 185558. Barcelona: Universitat Autonoma de Barcelona.

Rudman, Laurie A., and Julie E. Phelan. 2010. "The Effect of Priming Gender Roles on Women's Implicit Gender Beliefs and Career Aspirations". Social Psychology 41 (3): 192-202.

Smyth, Ron, and Henry Rogers. 2002. "Phonetics, Gender, and Sexual Orientation". In Actes de l'ACL2002/2002 CLA proceedings: 299-311.

Strand, Elizabeth A. 1999. "Uncovering the Role of Gender Stereotypes in Speech Perception". Journal of Language and Social Psychology 18 (1): 86-89.

Sulpizio, Simone, Fabio Fasoli, Ann Maas, Maria-Paola Paladino, Francesco Vespignani, Friederike A. Eyssel, and Dominik Bentler. 2015. "The Sound of Voice: Voice-based Categorization of Speakers' Sexual Orientation within and Across Languages." PLoS ONE 10(7): eo28882. DOI 10.1371/journal. Pone.0128882.

Terango, Larry. 1966. "Pitch and Duration Characteristics of Oral Reading of Males on a Masculinity- Femininity Dimension". Journal of Speech Language and Hearing Research 9 (December): 590-595.

“Thailand's LG Bт Communities Continue to Face Social Stigma Despite Visibility: Comprehensive UN-US Country Report". Retrieved from http://www.asiapacific.undp.org/content/rbap/en/home/presscenter/pressreleases/2014/og/16/ thailand-s-lgbt-communities-continue-to-face-social-stigma-despite-visibilitycomprehensive-un-us-country-report.html o8/og/19).

Valentova, Jaroslava Varella, and Jan Havlicek. 2013. "Perceived Sexual Orientation Based on Vocal and Facial Stimuli is Linked to Self-Rated Sexual Orientation in Czech Men." PLoS ONE 8: e82417. DOI: 10.1371/journal.pone.oo82417 PMID:2435818o. 
Von Hippel, William, Denise Sekaquaptewa, and Patrick Vargas. 1995. "On the Role of Encoding Processes in Stereotype Maintenance.” Advances in Experimental Social Psychology 27: 177-254.

Wardhaugh, Ronald, and Janet M. Fuller. 2015. An Introduction to Sociolinguistics (7th ed). Chichester: John Wiley \& Sons.

"Why is Bangkok such a Gay-Friendly City?". Retrieved from https://www.expique. com/blog/2016/o1/16/why-is-bangkok-such-a-gay-friendly-city/o8/og/19.

Zimman, Lal. 2013. "Hegemonic Masculinity and the Variability of Gay-Sounding Speech: The Perceived Sexuality of Transgender Men." Journal of Language and Sexuality 2: 1-39. 